\title{
Paisajes agrarios del segundo milenio de la era en el sector norte del Valle de Tafí (Tucumán, Argentina)
}

\section{Agrarian landscape of the second millennium in the northern area of Tafi Valley (Tucumán, Argentina)}

\author{
Valeria Franco Salvi ${ }^{1}$ y Rocío María Molar ${ }^{2}$
}

\section{Resumen}

Este artículo se propone discutir los resultados de investigaciones arqueológicas realizadas en el sector norte del valle de Tafí, enfocándonos específicamente en evidencias de las actividades agrícolas correspondientes a la primera mitad del segundo milenio de la era cristiana. Durante este período el paisaje agrario se transforma segregándose del sector de viviendas, lo que ha generado diversas explicaciones en la literatura arqueológica del Noroeste Argentino. Hemos llegado a la conclusión preliminar de que el valle adquiere una lógica espacial que es propia de este período en la región, pero que no habría sido originada por los factores que la arqueología tradicional suele atribuirle, esto es, la presión demográfica, conflictos o cambios ambientales.

Palabras claves: paisaje agrario, segundo milenio de la era cristiana, valle de Tafí, estrategias productivas.

\begin{abstract}
This paper proposes to discuss the results of archaeological research carried out in the northern sector of the Tafi valley, specifically focusing on evidences corresponding to the first half of the Second Millennium of the Christian Age. During this period, the agrarian landscape is segregating of household area which has generated several explanations in the archaeological literature of the Northwest Argentina. We came to the preliminary conclusion that the valley acquires a spatial logic, typical of this period in the region, but would not have been caused by factors that traditional archaeology usually attribute, this are population pressure, conflict or environmental changes.
\end{abstract}

Keywords: agrarian landscape, second millennium AD, Tafí valley, productive strategies.

Recibido: 24 abril 2016. Aceptado: 29 marzo 2017.

1 CONICET. Universidad Nacional de Córdoba. Copiapó 678, Córdoba 5000. ARGENTINA. Email: valefrancosalvi@unc.edu.ar.

2 CIFFYH-SECYT. Universidad Nacional de Córdoba. Paraná 185, Córdoba 5000. ARGENTINA. Email: romariamolar@gmail.com 


\section{Introducción}

El valle de Tafí, ubicado al oeste de la Provincia de Tucumán $^{3}$ (Figura 1), fue ocupado en algunos sectores desde momentos muy tempranos, que se remontan al menos a 7 mil años atrás (Martínez et al., 2013) continuando con algunas intermitencias hasta la actualidad. Esto lo hace un caso interesante para pensar las formas y lógicas de estructuración del paisaje y su relación con las contingencias políticas a nivel regional. El paisaje agrario, tal como se observa en el presente, es el resultado de siglos de trabajo llevado a cabo por "comunidades de práctica", esto es, colectivos (Latour, 1999, 2000 y 2005) que surgen de los modos en que las personas se involucran en compromisos mutuos definidos y sostenidos de la práctica (Hendon, 2010). Generalmente es estudiado desde una visión estática, como si estuviese congelado en el tiempo, sin considerarse la posibilidad de una trayectoria diacrónica en su historial. Quesada (2005) enfatiza el carácter dinámico de estos espacios, describiéndolos como instantáneas de momentos particulares y/o diversas depositaciones que incluyeron años de construcción, uso, abandono y reutilización, es decir, una acumulación de trabajo campesino. Tomando en cuenta este concepto, consideramos que en el valle se manifiesta un paisaje agrícola de larga duración, que inicia hacia el 200 AC aproximadamente y perdura hasta el presente en diversas formas, escalas y relaciones (Franco Salvi y Berberián, 2011; Franco Salvi, 2012).

El estudio de las ocupaciones del primer milenio de la era presenta relevancia en la literatura arqueológica del valle, principalmente por tratarse de poblaciones que construyeron aldeas con grandes viviendas de piedra y esculturas de gran tamaño. Asimismo, el registro arqueológico permite dar cuenta de la presencia de poblaciones del segundo milenio (Manasse, 1997, 2011; Páez, 2014; Páez y Plá, 2015; Patané Aráoz, 2008-2010), que llevaban a cabo otras dinámicas de ocupación del espacio en sintonía con fenómenos que se despertaban en la región relacionados a un aumento de la densidad poblacional, conflictos, limitaciones de carácter ambiental y nuevas lógicas políticas dirigidas a reproducir intereses de algunos sectores sociales específicos (Tarragó, 1999, 2000).

3 Coordenadas: $26^{\circ} 44^{\prime} 11^{\prime \prime} S-65^{\circ} 45^{\prime} 48^{\prime \prime} \mathrm{O}-26^{\circ} 56^{\prime} 58 \mathrm{SS}$ $65^{\circ} 40$ '06"O.
El fin del primer milenio de nuestra era dio lugar a cambios bruscos en las características, tamaño y distribución de los asentamientos humanos, un fenómeno que deja entrever importantes transformaciones en la sociedad a nivel regional (Nielsen, 2007). Entre los siglos X y XV, en numerosos sectores del NOA se institucionalizan nuevas formas de trabajo en la organización de la producción agrícola. A diferencia de períodos anteriores en los que la agricultura era una práctica a nivel doméstico donde primaba el cultivo a pequeña escala, esto es, la vivienda y su chacra (Quesada y Korstanje, 2010; Franco Salvi, 2012), en este momento se habría iniciado un proceso de segregación de espacios y de nuevas formas de articulación de áreas de producción. Este fenómeno ya se venía manifestando en algunos sectores durante momentos previos (Caria et al., 2010; Scattolin, 2001, 2010; Korstanje, 2005; Oliszewski, 2011; Di Lullo, 2012), aunque toma fuerza y se consolida en el Tardío o período de Desarrollos Regionales.

En esta oportunidad, se presentan evidencias de ocupaciones humanas temporarias correspondientes al segundo milenio en el valle de Tafí. Lo que buscamos dilucidar es el contexto político en el que se abordaron estos proyectos agrícolas, esto es, si fueron parte de un proceso local o si corresponden a la logística de organizaciones sociales implementadas por poblaciones de valles contiguos (i.e. valle de Santa María $\left.{ }^{4}\right)$.

4 En el valle de Santa María se inicia un proceso de consolidación de grandes poblados que destinaron espacios específicos para la producción agrícola y pastoril. En ese contexto, se habrían gestado poblados centralizados con poder militar y religioso, y que extendían su control directo sobre instalaciones más pequeñas de explotación económica: tierras de cultivo y pasturas (Nastri, 2005). Esta área emplazada a $40 \mathrm{~km}$ de distancia del valle de Tafí presenta un proceso histórico inverso al del valle de Tafí, esto es, pequeños asentamientos durante el primer milenio y un aumento sustancial en el segundo cuando comenzó a transformarse en uno de los paisajes más densamente poblados del Noroeste Argentino prehispánico (González y Tarragó, 2005). Asimismo, pese a su proximidad espacial presentan diferencias ambientales de gran contraste, registrándose en Santa María condiciones de gran aridez mientras que en Tafí el ambiente es húmedo y con condiciones más benignas para la producción agrícola. 


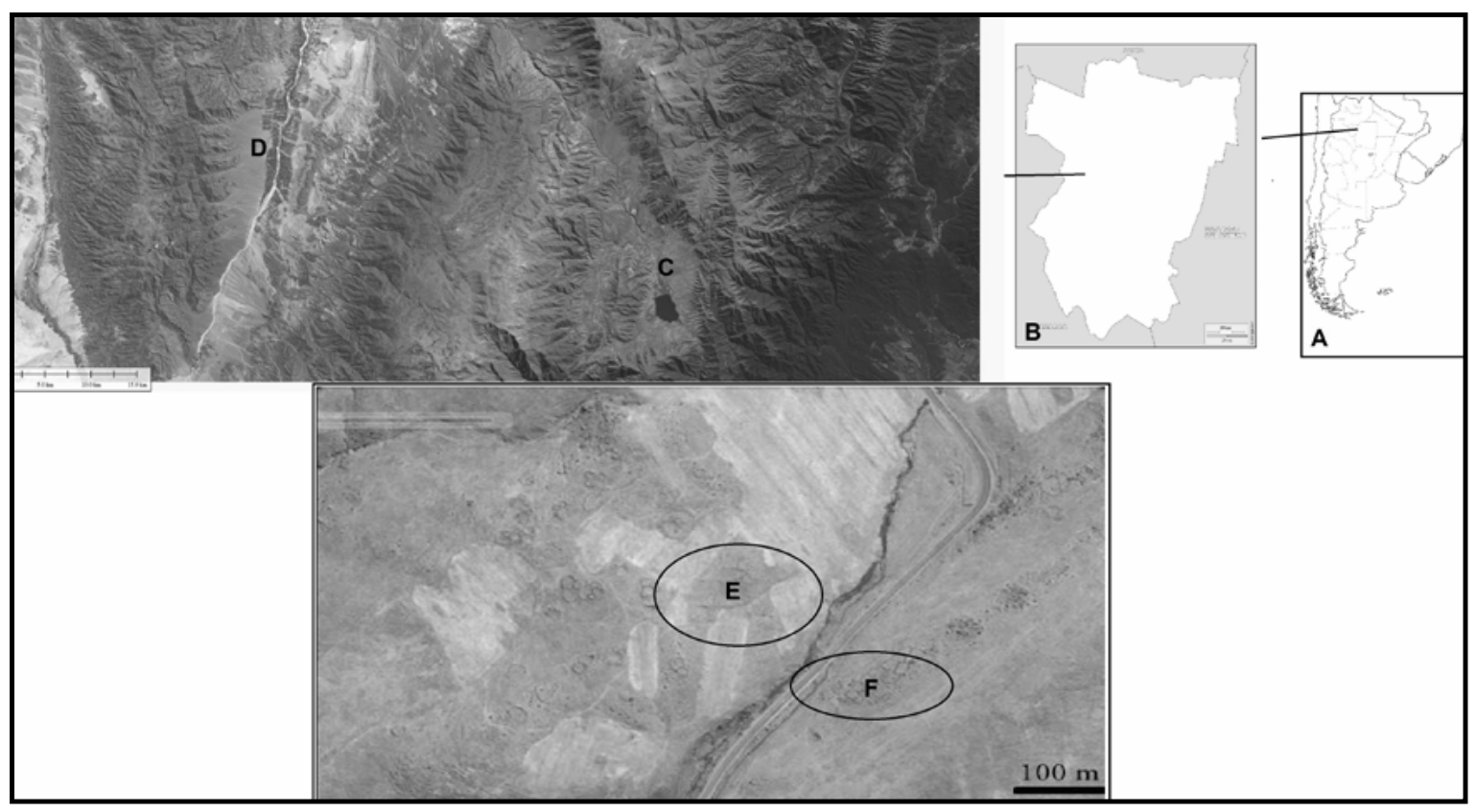

Figura 1. A. República Argentina. B. Provincia de Tucumán. C. valle de Tafí. D. valle de Santa María. E. Estructura Excepcional La Bolsa 3. F. Estructura Excepcional La Bolsa 2.

En el valle de Tafí no se observan centros poblados de gran envergadura, aunque en algunos sectores se detectaron varios núcleos poblacionales aglutinados en función de -o en relación con- espacios destinados a la agricultura (Manasse, 2007, p. 147). Investigaciones arqueológicas intensivas (Manasse, 2011, 1997, 2007) corroboran ocupaciones tardías producto de la continuidad con las del primer milenio de la era, pero a una escala mucho menor con baja densidad poblacional. Los estudios realizados en el sector norte del valle (Salazar, 2010; Franco Salvi y Berberián, 2011) nos llevan a considerar este planteo y sostener como hipótesis de trabajo la ausencia de influencias extralocales. En este sentido, nos proponemos indagar en este punto, diferenciando los cambios y continuidades en las ocupaciones prehispánicas del área norte, centrándonos especialmente en las prácticas agrícolas.

El registro material que se presenta en este artículo se corresponde con un espacio de corto uso, que se limita al momento de mayor demanda en la producción. Las dataciones radiocarbónicas nos llevan a estimar que fue ocupado en algún momento del siglo XIII, un período particular en el NOA por la sequía imperante (Caria y Garralla, 2003; Sayago et al., 2003) y por potenciales conflictos (Nielsen, 2009-2011). Para estos momentos son numerosas las evidencias de ocupación que se registran en el valle, siendo la cerámica y la arquitectura los principales indicadores. Manasse (2011) ha detectado diferentes sitios (i.e. Barrio Malvinas, Casas Viejas, El Mollar, Tafí Nuevo, La Costa 1, Los Castaños) en los que se destaca la presencia de unidades cuadrangulares de piedra aglomeradas asociadas a cerámica con rasgos de estilo santamariano, famabalasto negro sobre rojo, belén, ordinaria con base en pie de compotera, etcétera, similares a las presentes en otros sitios contemporáneos (Manasse, 2011). Asimismo, se han realizado dataciones radiocarbónicas sobre restos óseos y macrorrestos en un sector de entierros en el sitio Los Cuartos, al sureste del valle, constatando ocupaciones del período Tardío. Muy próximo a este sitio se encuentra el Pukara de Las Lomas Verdes (Patané Aráoz, 2008-2010) el cual presentó, en superficie y excavación, cerámica foránea (p.e. Inka Cuzqueño, Inka Pakajes) siendo, en primera instancia, una expresión de relaciones mantenidas entre este territorio y otros sectores provinciales y centrales del Imperio incaico (Patané Aráoz, 2008-2010). 


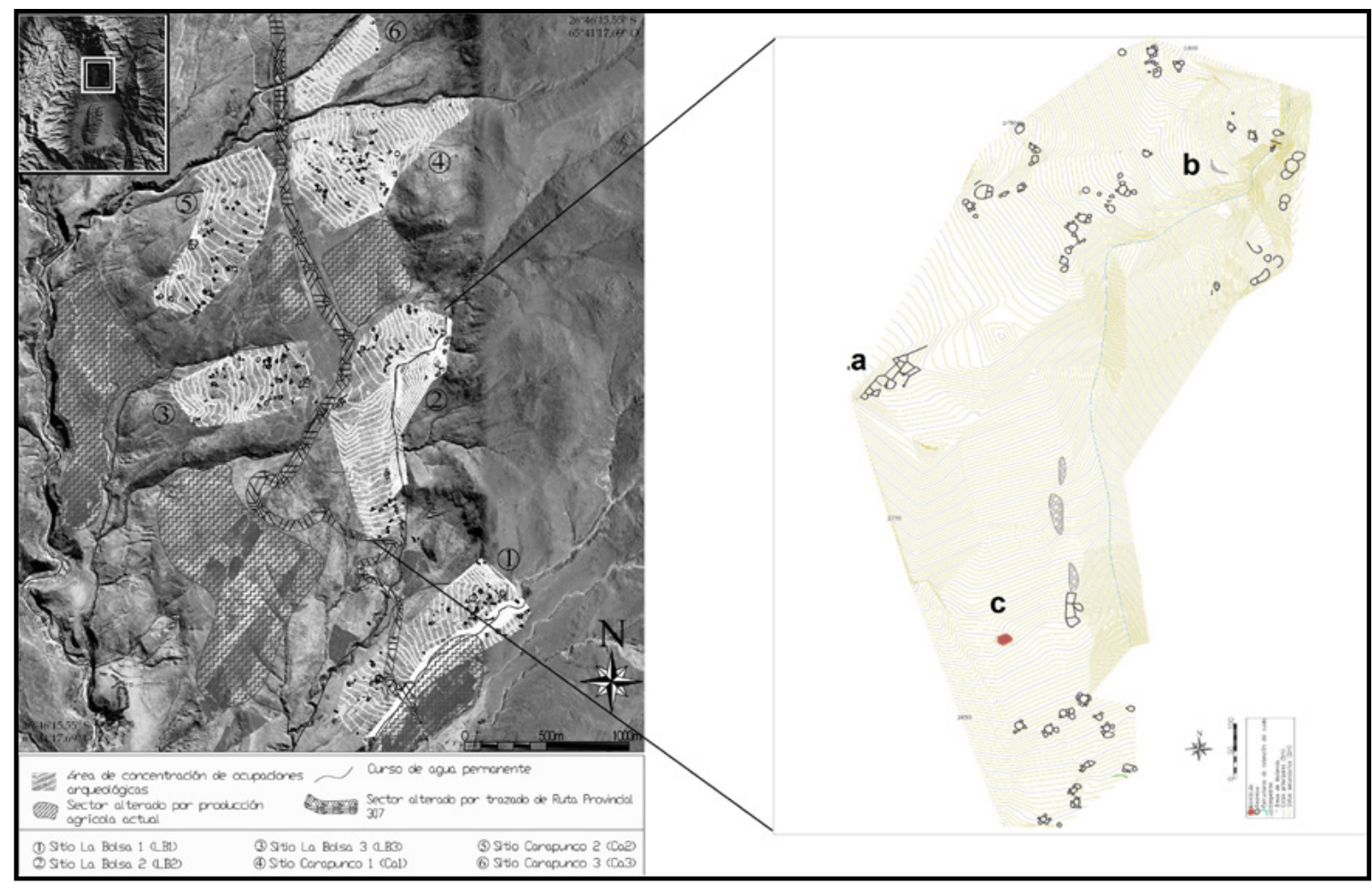

Figura 2. Área norte del valle de Tafí. Sectores La Bolsa y Carapunco.

\section{Evidencias de ocupaciones tardías en los sitios La Bolsa 2 y La Bolsa 3}

El área norte del valle de Tafí fue incorporada en la narrativa arqueológica como un espacio de actividades económicas especializadas en el pastoreo (Berberián y Nielsen, 1988; Berberián y Giani, 1999; Sampietro Vattuone, 2002). El argumento fundamental giró en torno a los datos geológicos, geomorfológicos, ambientales y ecológicos, agregándose las observaciones superficiales de grandes recintos subcirculares elípticos y cuadrangulares emplazados en cotas altas. Berberián y Nielsen (1988) caracterizaron los tipos de asentamiento presentes en el valle a partir de la asociación de estructuras y biotopos. Plantearon que en el sector norte prevalecieron unidades de residencia permanente compuestas por recintos circulares adosados y unidades cuadrangulares constituidas por dos o más recintos grandes, con puertas y recintos circulares pequeños anexados, interpretados como "corrales". Por medio de estudios experimentales y observaciones en el terreno, sostuvieron que la agricultura en La Bolsa y Carapunco habría sido practicada mediante un sistema agrícola de baja inversión tecnológica, siendo innecesarias las labores especiales de construcción de estructuras de riego o retención del suelo. Posteriormente Sampietro Vattuone (2002) basándose en estudios geomorfológicos señaló que en este sector no se presentaron prácticas vinculadas a la agricultura. Frente a estos antecedentes, se llevaron a cabo estudios que incluyeron prospecciones, relevamientos planialtimétricos y recolecciones superficiales centrados en su detección (Franco Salvi et al., 2014). En los sectores Carapunco y La Bolsa (Figura 2) es posible reconocer una amplia gama de medios constructivos y soluciones de diseño edilicio, así como numerosas formas de apropiación del paisaje. Resulta clara la presencia recurrente de despedres, muros de contención, cuadros de cultivo, andenes y recintos circulares/subcirculares simples (Franco Salvi y Berberián, 2011). Las recolecciones superficiales nos han permitido acotar la cronología de estas estructuras de manera predominante al primer milenio de la era, detectándose en mínima medida cerámica tardía o 
estructuras de arquitectura excepcional, ${ }^{5}$ similares a las correspondientes al período de Desarrollos Regionales y colonial.

\section{Sitio arqueológico La Bolsa 2 (LB 2)}

El sitio arqueológico LB 2 (S 2647’39.99”-W $\left.65^{\circ} 43^{\prime} 40.63^{\prime \prime}\right)$ está emplazado sobre un glacis cubierto en torno a un arroyo que corre en dirección norte-sur. Se encuentra conformado por numerosas unidades residenciales (de entre tres y doce recintos cada una), aterrazamientos, montículos de despedre, afloramientos con morteros, muros lineales de piedra para la contención del suelo, cuadros de cultivo y una serie de estructuras de manejo del agua (ver Figura 2). Asimismo, se registraron espacios "vacíos", sin arquitectura, en superficies con poca pendiente (entre 8 y 15\%), que posiblemente fueron utilizados para el cultivo sin la necesidad de incorporar algún tipo de tecnología específica. De acuerdo a las características de la arquitectura y la cerámica, se puede afirmar que la ocupación principal del sitio se llevó a cabo durante el primer milenio de la era. Se contabilizaron un total de 17 unidades residenciales tipo $3,{ }^{6}$ un cuadro de cultivo, afloramientos con morteros, una estructura cuadrangular compuesta, numerosos recintos circulares grandes aislados y adosados a otros de diversos tamaños de planta circular y subcircular y recintos de planta subcuadrangular y circular en cotas altas. En esta sección, se registró una estructura de piedra semicircular de $18,20 \mathrm{~m}$ de largo y $0,86 \mathrm{~m}$ de alto que, de acuerdo a sus características arquitectónicas, habría sido utilizada para contener o regular el curso del agua. En investigaciones anteriores, Berberián y su equipo excavaron la estructura a la que deno-

5 En el presente caso de estudio definimos como "estructura excepcional" todos aquellos recintos de piedra aglomerados con formas angulares/cuadrangulares que encierran grandes superficies, muy similares a los registrados para el PDR o Tardío (siglos X-XV) en el Noroeste Argentino (Berberián y Nielsen, 1988).

6 Conjuntos arquitectónicos compuestos por un recinto circular de grandes dimensiones (entre $8 \mathrm{~m}$ y $15 \mathrm{~m}$ de diámetro), al cual se adosa al menos una habitación de la misma morfología de menor tamaño (entre $2 \mathrm{~m}$ y $6 \mathrm{~m}$ de diámetro). En algunos casos, la cantidad de estructuras adosadas excede la decena, presentando diversidad en su construcción. Conforman espacios residenciales (Berberián y Nielsen, 1988). minaron "represa", detectando la presencia de gran cantidad de material arenoso en su base, lo cual se interpretó como un relleno generado por el almacenaje de agua (Berberián, 1994). Se obtuvo muy baja densidad de materiales arqueológicos, pero en su totalidad se trató de cerámica similar a las asociadas a las ocupaciones del primer milenio DC.

Algunas secciones del sitio están ocupadas exclusivamente por estructuras productivas, tanto agrícolas (Franco Salvi, 2012) como pastoriles (Chiavassa Arias, 2015), y por recintos cuadrangulares de gran tamaño que habrían sido de uso mixto. Además, en diferentes sectores del sitio se reconocieron despedres de tamaños variados (entre 20 y $100 \mathrm{~m}$ de longitud y 20 y $50 \mathrm{~m}$ de ancho). A diferencia de otros sitios, no se registraron prácticamente muros de contención, pese a mantener una pendiente que varía entre el 10 y $30 \%$.

A nivel espacial, las estructuras para el manejo del agua detectadas se asocian a estos recintos de planta subcuadrangular y circular emplazados en cotas altas y agrestes que se habrían utilizado para el pastoreo. El almacenaje hídrico en estos sectores debió haber sido una estrategia importante para organizar las tareas diarias de cuidado de animales y cultivos.

En el extremo sur del sitio se emplaza un montículo de grandes dimensiones, que se diferencia de los demás registrados en toda el área, los cuales se corresponden al producto de la limpieza de los campos de cultivo (Salazar, 2010). La estructura presenta una forma de planta subcircular alargada de $25 \mathrm{~m}$ de diámetro aproximadamente, y 2,5 m de altura. Su tamaño y disposición en un contexto libre de otras estructuras lo hacen ampliamente visible. Las similitudes con el montículo "El Mollar" (González, 1955; González y Núñez Regueiro, 1960) permiten proponer allí la realización de prácticas comunitarias, ${ }^{7}$ lo cual deberá corroborarse mediante la realización de excavaciones futuras. A pocos metros del lugar se registraron 10 unidades residenciales tipo 3 (Berberián y Nielsen, 1988), una estructura cuadrangular, un muro de contención

7 Se refieren a todas aquellas actividades-acciones que convocan a numerosas personas (más de una familia), poniéndose en juego los intereses colectivos. 
y dos recintos circulares de tamaño considerable. Por las condiciones de emplazamiento y las características de las instalaciones, se podría sostener que las viviendas están relacionadas con campos de cultivo, los cuales habrían requerido de dispositivos tecnológicos (palas) e infraestructura (terrazas, andenes, etc.) para poder ser sembrados.

En la totalidad del sitio se realizaron transectas de recolección superficial (Franco Salvi et al., 2014), recuperándose 291 fragmentos de cerámica. Las proporciones de grupos tecnotipológicos en la totalidad de las mismas es bastante homogénea, presentándose un alto porcentaje de fragmentos correspondientes a ordinario rojo sin baño $(\mathrm{ORsB})$ (entre $55,8$ y $91,2 \%)$ y, en menor proporción, rojo fino sin baño (RFsB) (entre 10,6 y 39,6\%).

Las formas arquitectónicas de las viviendas y los campos de cultivo se condicen en sus características con las registradas para el primer milenio (Franco Salvi, 2012). De igual manera, las materialidades recolectadas de dichas estructuras corresponden al pe- ríodo, lo cual reafirma la asignación cronológica de la ocupación principal (Berberián y Nielsen, 1988; Salazar, 2010).

\section{Ocupaciones del segundo milenio de la era}

Estructura "excepcional": alero-refugio y estructuras subcuadrangulares/cuadrangulares adosadas.

En una sección del sitio, a $200 \mathrm{~m}$ de la estructura monticular mencionada anteriormente, se reconoció un conjunto de 16 recintos de planta rectangular y muros con una tecnología adaptada al desnivel, disímiles a las formas arquitectónicas comúnmente encontradas en el área (Figura 3). En este mismo complejo se detectaron rasgos de una ocupación que aprovechaba un afloramiento rocoso similar a un alero al cual denominamos "alero-refugio". Esta estructura se ubica en un sector estratégico que le habría permitido a sus ocupantes realizar sus actividades productivas sin moverse del lugar.

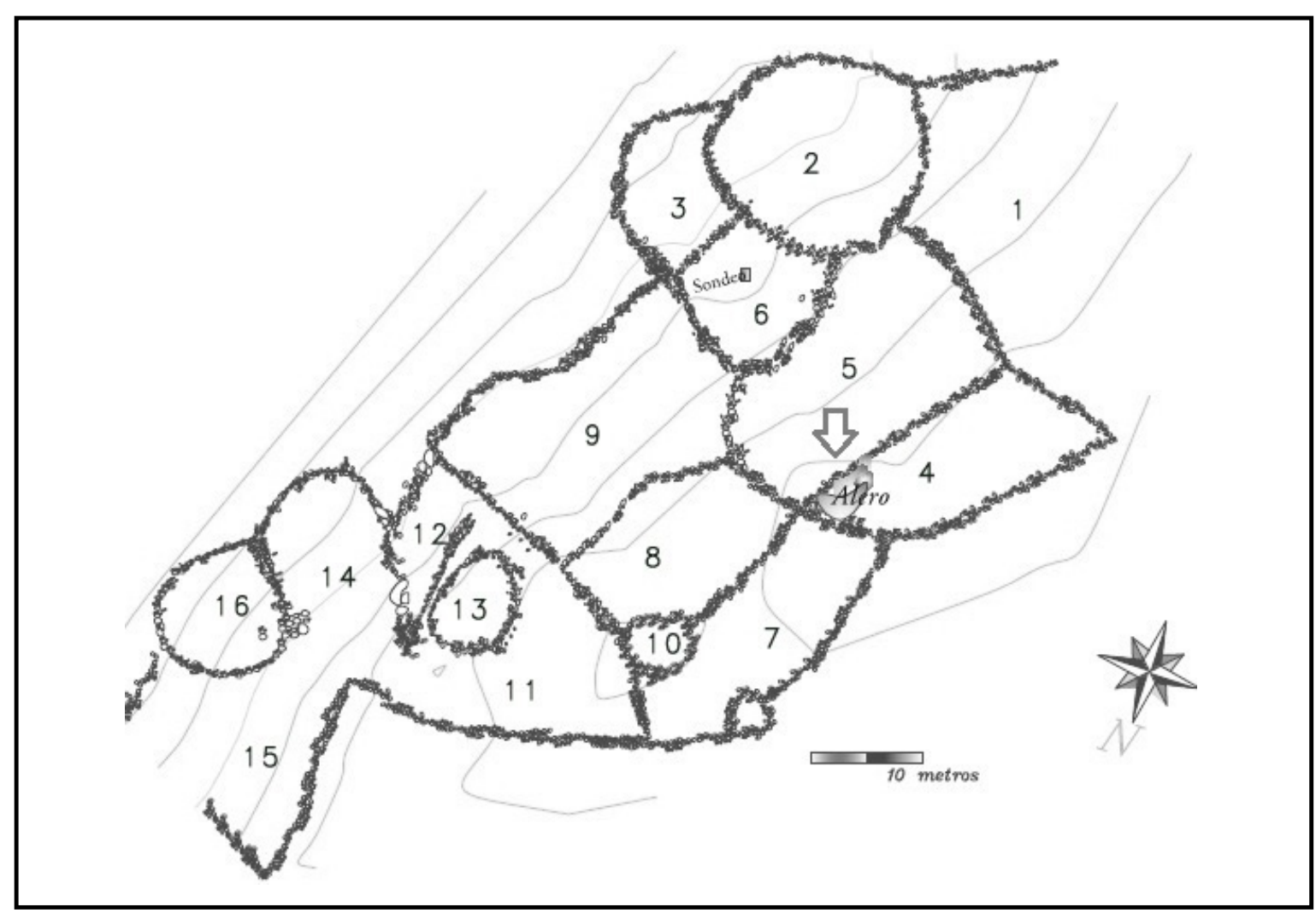

Figura 3. Estructura excepcional detectada en el sitio arqueológico La Bolsa 2. 
El conjunto de recintos se concentra en una superficie de 0,55 ha, lo que lo distingue de las demás estructuras, las cuales se asientan de forma dispersa. En este caso particular, se pierde la segregación $y$ desde el exterior se reconoce como unidad. Los muros son informales, pero requirieron del movimiento de un gran número de bloques rocosos para su construcción (esquistos micáceos y graníticos que abundan en el sitio y alrededores). Algunas paredes ubicadas de forma transversal a la pendiente presentan una forma zigzagueante, lo que habría permitido afrontar mejor el lavado del suelo e impedir el derrumbe de la estructura, favoreciendo su perduración en el tiempo.

\section{Recolecciones superficiales y excavaciones}

Se efectuaron recolecciones superficiales sistemáticas en la totalidad de la estructura excepcional, esto es, una superficie de $5524 \mathrm{~m} 2$ que cubrió los 16 recintos. La cerámica predominante detectada corresponde a la del tipo Ordinaria Roja sin Baño (ORsB) y Roja Fina sin Baño (RFsB). No obstante, también se levantaron materiales diagnósticos del tipo Santa María Bicolor (SMB) (recinto 5, 7, 9 y 12) Rojo Fino con Baño Blanco (RFcBB) (recinto 1, 8 y 9) y Rojo Grueso con Baño Negro (RGcBN) (Tabla 1). Estos fragmentos, que por sus características se corresponden a la primera mitad del segundo milenio, fueron reconocidos solamente en la sección que ocupa esta estructura excepcional, sin encontrarse en los demás sectores del sitio, lo cual sería coherente ya que la arquitectura corresponde a momentos precedentes.

Con el objetivo principal de reconocer el uso de esta estructura excepcional y las materialidades relacionadas, se procedió a la excavación del "alero-refugio" $y$ al sondeo de un recinto asociado (Recinto 6, en adelante R6). Para la selección de las áreas excavadas se tuvieron en cuenta una serie de criterios: su emplazamiento, relación con otras construcciones, tipología, accesibilidad y dimensiones.

El alero-refugio (Figuras 3 y 4 ) es un espacio acotado de $5 \mathrm{~m} 2$ que habría alojado a un número reducido de personas. Su posición le permite visualizar la mayoría de los recintos que conforman este conjunto y acceder a ellos de manera constante, sin el requerimiento de una logística para el traslado. La estructura está semicerrada por una hilera de piedras o muro bajo $(0,50 \mathrm{~m})$ construido de manera expeditiva.

Tabla 1. Características de la cerámica recolectada en la estructura excepcional

\begin{tabular}{|c|c|c|c|c|c|c|c|c|c|c|c|c|c|c|c|c|c|}
\hline $\begin{array}{l}\text { Cerámica } \\
\text { superficial }\end{array}$ & $\begin{array}{l}\mathrm{R} \\
\mathbf{1}\end{array}$ & $\begin{array}{l}\mathbf{R} \\
2\end{array}$ & $\begin{array}{l}\mathbf{R} \\
3\end{array}$ & $\begin{array}{l}\mathrm{R} \\
4\end{array}$ & $\begin{array}{l}\mathrm{R} \\
5\end{array}$ & $\begin{array}{l}\mathrm{R} \\
6\end{array}$ & $\begin{array}{l}\mathbf{R} \\
7\end{array}$ & $\begin{array}{l}\mathbf{R} \\
\mathbf{8}\end{array}$ & $\begin{array}{l}\mathbf{R} \\
9\end{array}$ & $\begin{array}{l}\mathrm{R} \\
10\end{array}$ & $\begin{array}{l}\mathrm{R} \\
11\end{array}$ & $\begin{array}{l}R \\
12\end{array}$ & $\begin{array}{l}R \\
13\end{array}$ & $\begin{array}{l}R \\
14\end{array}$ & $\begin{array}{l}\mathrm{R} \\
15\end{array}$ & $\begin{array}{l}R \\
16\end{array}$ & $\begin{array}{l}\mathbf{R} \\
17\end{array}$ \\
\hline ORsB & 2 & - & - & - & - & 4 & - & 7 & 35 & - & 225 & 7 & - & - & - & 2 & 2 \\
\hline RFsB & 1 & 1 & - & - & - & 1 & 3 & - & 7 & - & 25 & 2 & - & - & - & - & - \\
\hline ORcBR & - & - & - & - & - & - & - & - & - & - & 20 & - & - & - & - & - & - \\
\hline RFcBR & - & - & - & - & - & - & - & - & - & - & 24 & - & - & - & - & - & - \\
\hline Gris Fino & - & 1 & - & - & - & - & - & - & - & - & - & - & - & - & - & - & - \\
\hline OG & - & - & - & - & - & - & - & - & - & - & - & - & - & - & - & - & - \\
\hline BsRP & - & - & - & - & - & - & - & - & - & - & - & - & - & - & - & - & - \\
\hline SMB & - & - & - & - & 1 & - & 1 & - & 2 & - & - & 1 & - & - & - & - & - \\
\hline $\mathrm{RFcBB}$ & 1 & - & - & - & - & - & - & 1 & 3 & - & - & - & - & - & - & - & - \\
\hline $\mathrm{RGcBN}$ & 1 & - & - & - & - & - & - & - & - & - & - & - & - & - & - & - & - \\
\hline
\end{tabular}




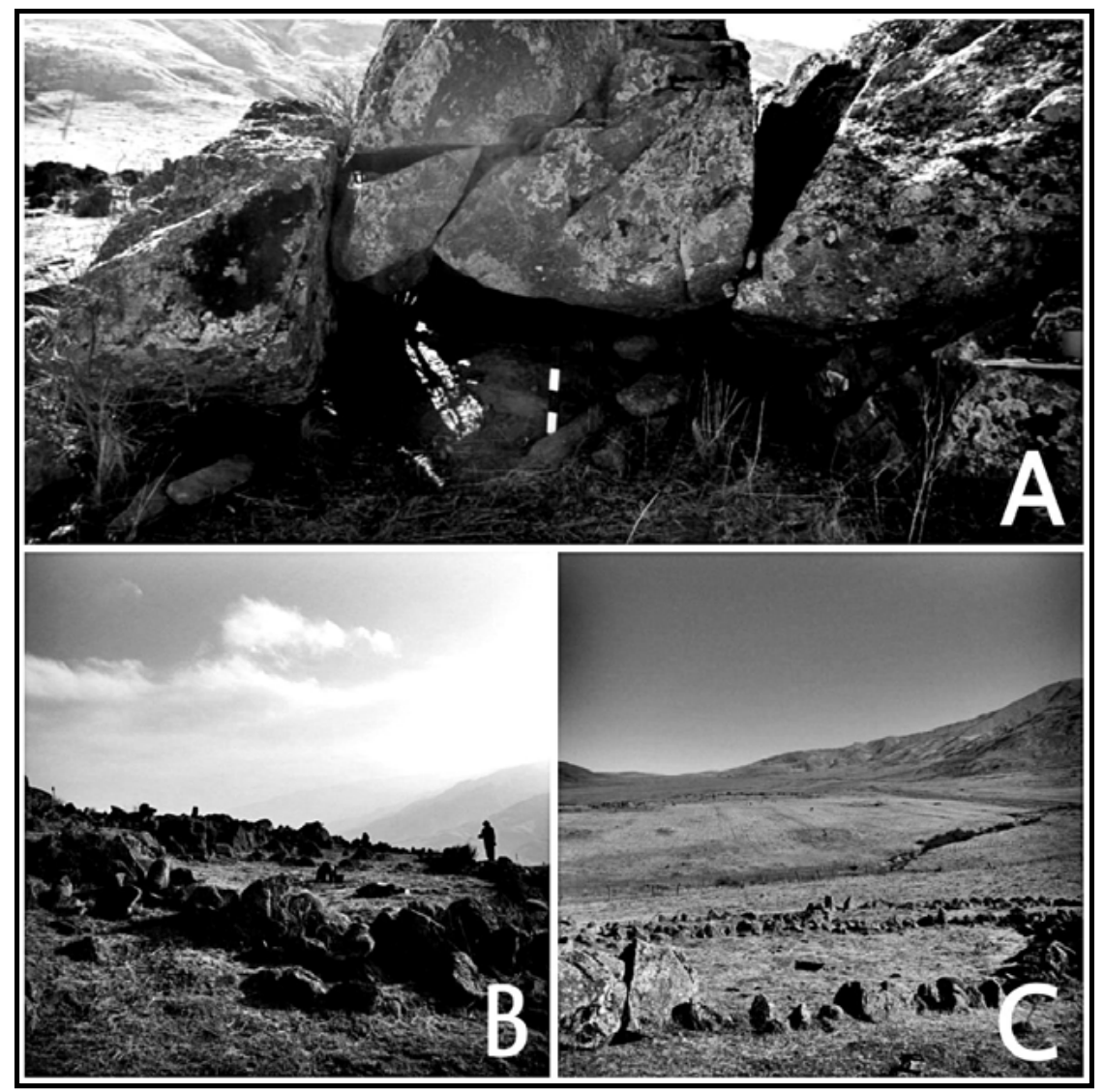

Figura 4. A. Vista frontal del "alero-refugio". B. R6.

C. Vista del R6 desde el "alero-refugio".

En el sector que encierra la línea de goteo del "alerorefugio" se reconocieron en la superficie pequeños fragmentos de cerámica pintada similar a la del tipo Santa María Bicolor (SMB). Posteriormente se procedió a la demarcación de cuadrículas haciendo un total de $4^{\mathrm{m} 2}$ de área de excavación (Figura 5). Las intervenciones efectuadas siguieron los estratos naturales junto a un detallado registro tridimensional de rocas de derrumbes, rasgos, materiales arqueológicos y evidencias de alteraciones posdeposicionales. Esta información fue sustancial para determinar eventos constructivos, áreas de actividad y prácticas de mantenimiento, abandono y reocupación. La totalidad de estratos, rasgos e interfacies fueron considerados como unidades estratigráficas (UE), e incluidos en una representación en forma de diagrama (Harris, 1991; Carandini, 1997) que permitió construir una secuencia biográfica de la estructura desde su construcción hasta nuestra intervención.
La superficie de excavación inicialmente iba a ser mayor, pero en el ángulo sur asomaba la roca madre que redujo el potencial de excavación. Se detectaron cuatro unidades estratigráficas (UE): la primera unidad (UE100) correspondía al nivel superficial con un bajo grado de compactación y una coloración brownish gray (HUE 5yr 4/1). Se reconocieron en el depósito algunas raíces y piedras de diferentes tamaños que habrían sido parte de un pequeño derrumbe de un muro informal (UE103). Asimismo, se obtuvo un gran porcentaje de cerámica de grupos tecnotipológicos del tipo ordinario rojo fino pintado (ORFP) asignables al segundo milenio de la era.

La siguiente unidad (UE101), desde los 30 hasta los $78 \mathrm{~cm}$ de profundidad, era más compacta y su coloración más oscura (i.e. HUE $5 y r$ 2/3) que la anterior. Este depósito estaba asociado a piedras que habrían formado parte del muro informal que 


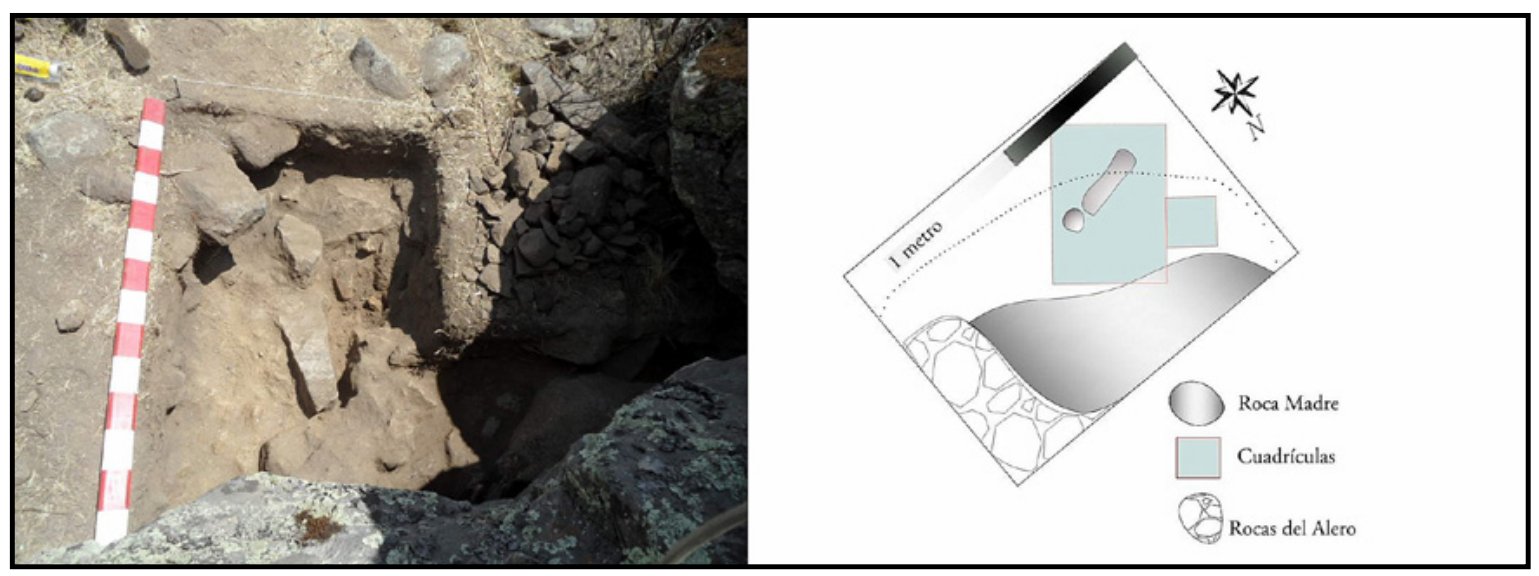

Figura 5. Plano de planta del área excavada (alero-refugio, Sitio La Bolsa 2).

encerraba el alero (UE103) (Figura 6). Los materiales arqueológicos fueron diversos, destacándose dos puntas triangulares apedunculadas y escotadas de obsidiana, ${ }^{8}$ fragmentos cerámicos del tipo Santa María Bicolor y en menor proporción ordinario rojo grueso sin engobe. También se registraron espículas de carbón que fueron mapeadas y recolectadas, obteniéndose una datación absoluta mediante $\mathrm{C}^{14}$ AMS en AA106105. La muestra de carbón vegetal fue fechada en $696 \pm 35 \mathrm{AP}$; con $68,2 \%$ de confianza; $1294-1320$ DC y $1351-1386$ DC con un $95,4 \%$ de probabilidades, dando como resultado un rango entre 1286-1392 DC.

Los análisis de variabilidad tecnológica del conjunto cerámico (realizados mediante la caracterización de cortes frescos en lupa binocular a bajos aumentos) recuperado en esta unidad permitieron identificar la existencia de al menos dos grandes clases tecnológicas asociadas a la selección y procesamiento del material plástico y las inclusiones: una fina (inclusiones finas de mica, cuarzo y negras laminares, distribuidas regularmente, con densidades bajas de 3 a $10 \%$ y estructura compacta; cocción oxidante predominantemente uniforme, aunque en ocasiones presenta núcleos grises), que es la que se asocia a la decoración santamariana, y una gruesa (inclusiones no uniformes gruesas de mica, cuarzo y negras laminares, dis-

8 Análisis de procedencia realizados mediante métodos analíticos de fluorescencia por rayos $\mathrm{X}$ indican que la obsidiana procede de la Fuente Ona (Puna meridional argentina, sector norte de la Provincia de Catamarca) (Glascock, 2016). tribuidas de manera irregular y con densidades entre 15 y $30 \%$, con una proporción importante de porosidades esferoidales y alargadas, de textura porosa, cocidas en atmósferas oxidantes predominantemente uniformes) que no cuenta con decoraciones y en algunos casos presenta sus superficies alisadas por marleados. Si bien la clase fina tiene en algunas ocasiones decoraciones que son privativas del segundo milenio de la era y son típicas de los grandes asentamientos del vecino valle de Yocavil (Marchegiani et al., 2009), sus antiplásticos y textura son muy similares a los grupos tecnológicos que observamos en los sitios aldeanos del norte de Tafí (Salazar et al., 2007) (Figura 7). Esto último, que debería contrastarse en el futuro con estudios más específicos, podría llevar a pensar que al menos hay una continuidad en el uso de fuentes de arcilla y/o antiplásticos con respecto a los grupos locales previos, lo que indicaría, en principio, una producción local.

Los estudios morfológicos, por su parte, indican que el conjunto detectado corresponde a pequeños cuencos, pucos y ollas que no habrían abastecido más que a pocas personas. La baja densidad de materiales nos lleva a inferir actividades de cocción y consumo, pero a baja escala y de forma esporádica. Un ejemplo es la presencia de un fragmento de base de una olla pedestal u "olla de pie de compotera" que por su pequeño volumen habría sido utilizada para cocinar el alimento de una o dos personas (Williams et al., 2005; Orgaz, 2012; Giovanetti et al., 2013). En este sentido, los restos arqueológicos concuerdan con la ocupación ocasional del alero. 


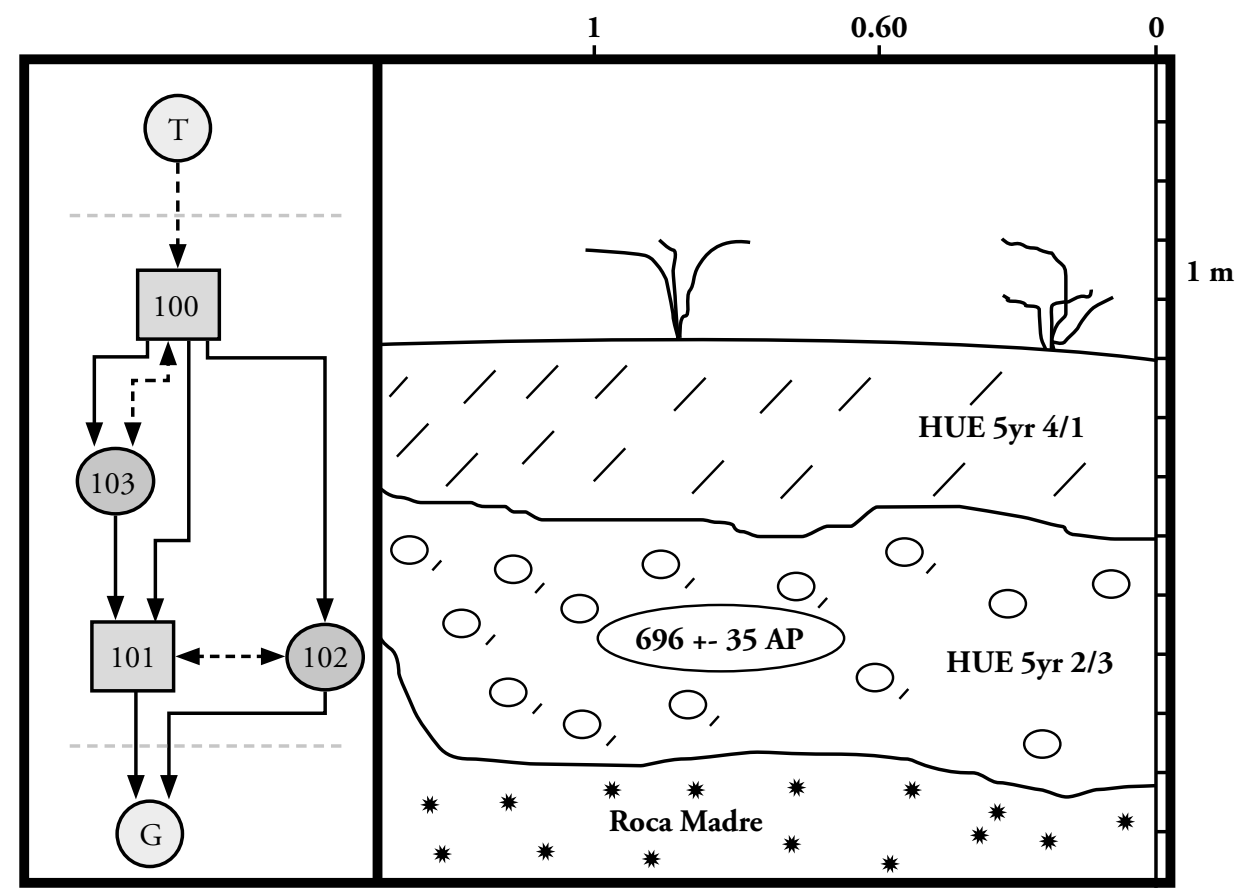

Figura 6. Perfil norte y matriz de Harris de la excavación realizada en el "alero-refugio".

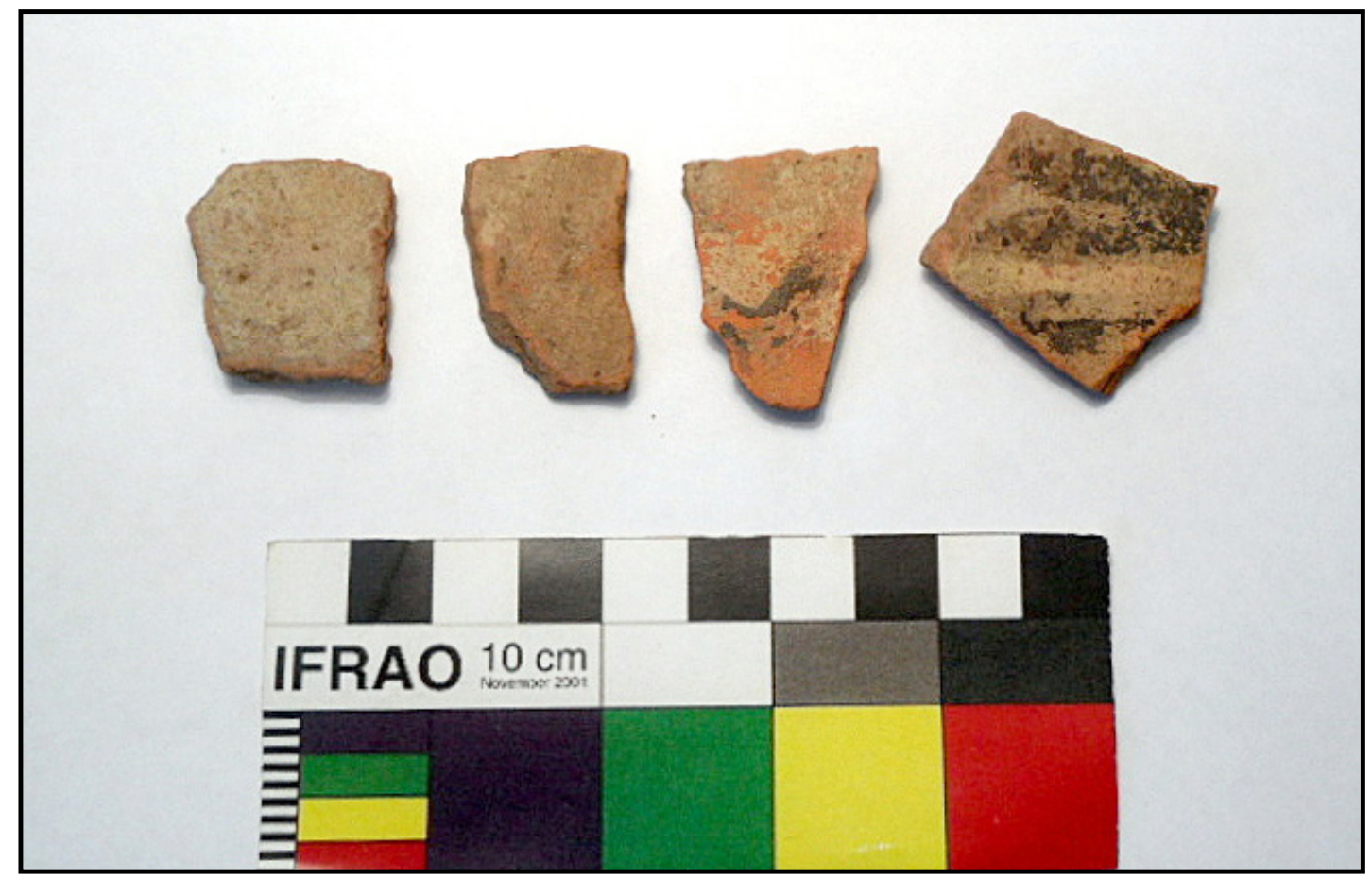

Figura 7. Fragmentos cerámicos obtenidos de la UE 101 (alero-refugio, Sitio La Bolsa 2). 
A fin de aproximarnos al conocimiento del uso de esta estructura excepcional y su marco temporal, se realizó un sondeo de $1 \mathrm{~m}$ x 0, $8 \mathrm{~m}$ en el R6 (ver Figura 3). Fue una excavación inicial, en la que se siguieron estratos artificiales de $20 \mathrm{~cm}$ obteniéndose exclusivamente restos cerámicos en escasa cantidad, con características similares a los hallados en superficie.

En ambas excavaciones, se extrajeron muestras de suelos a nivel horizontal y vertical, para luego realizar el análisis arqueobotánico de microfósiles (Korstanje, 2009; Korstanje y Cuenya, 2010). En el caso del alero-refugio, los estudios dieron como resultado la presencia de sílicofitolitos no articulados, granos de almidón, espículas de esponja y diatomeas. Los morfotipos de fitolitos se corresponden con los característicos de algunas de las poáceas de la región (Panicoideas y Chloroideas), y uno posible de asociar a Zea mays sp. (Pearsall et al., 2003). Respecto a los almidones, de los siete visualizados, cuatro pudieron ser identificados teniendo en cuenta su tamaño (de entre 15, 2 y $20 \mu \mathrm{m}$ ), la cruz de extinción (con ángulos de $90^{\circ}$ ) y el hilum en forma de punto, correspondiendo a Zea mays sp. (Korstanje y Babot, 2007).

En cuanto a las muestras provenientes del R6, los análisis también dieron como resultado la presencia de silicofitolitos de gramíneas, y dos pertenecientes a Zea mays. Además, en las distintas muestras se hallaron diatomeas, las cuales de acuerdo a Korstanje (2005) serían en principio un indicador de humedad en los suelos. En este caso fueron identificadas como Bacillariophyceae pennales, de los tipos Surirella y Synedra, las cuales se encuentran en agua dulce (McLaughlin, 2012).

Sin embargo, los bajos porcentajes de diatomeas en sedimentos (menos de un $2 \%$ del total de los microrrestos) y la ausencia de canales de riego nos llevan a pensar que el riego fue a secano, hipótesis que requiere de mayor profundización y análisis en el futuro. Es de destacar que no se hayan encontrado esferulitas (microfósiles de origen animal), ya que esto indicaría que no se estaban utilizando abonos naturales, como guano o excremento de herbívoros, para mejorar la fertilidad de la tierra (Korstanje, 2009). Además, su ausencia dificulta pensar en una utilización mixta del recinto, es decir, que probablemente este espacio haya sido usado únicamente para el desarrollo de prácticas agrícolas, excluyendo el manejo de animales.

La presencia de granos de almidón de Zea mays sp. en el alero-refugio podría explicarse por su cercanía a los recintos destinados a la producción, aunque resulta difícil de corroborar esta hipótesis debido a que los gránulos no son volátiles. En este sentido, creemos que los maíces detectados fueron utilizados para el consumo humano, pudiendo haber sido trasladados por quienes utilizaron este espacio u obtenidos de las mismas plantas que estaban cuidando diariamente. El hallazgo de una mano de moler en el alero habilita pensar que en este lugar se realizó algún tipo de procesamiento de granos. Esta actividad pudo haber tenido lugar en algunos de los espacios de molienda del sitio, los cuales consisten en superficies pulidas de forma ovalada ubicadas sobre rocas metamórficas. Las características de estas horadaciones (con un diámetro de entre 15 y $25 \mathrm{~cm}$ y una profundidad de 1 y $2 \mathrm{~cm}$ ) permiten pensar que las cantidades procesadas eran pequeñas, o que estos morteros fueron utilizados para un procesamiento final de granos que ya habían sido molidos con anterioridad (por ejemplo, para obtener un producto de tipo harinoso).

\section{Sitio arqueológico La Bolsa 3 (LB3)}

\section{Ocupaciones del primer milenio}

El sitio se emplaza a $200 \mathrm{~m}$ de LB2 en el lado oeste $\mathrm{y}$ ambos se posicionan separados por una ruta de trazado actual (Figura 8). Dentro de las numerosas construcciones identificadas es preciso destacar la presencia de 14 unidades residenciales, con características propias del primer milenio de la era, en asociación a nueve estructuras circulares grandes con diámetros que superan los $6 \mathrm{~m}$. Contiguo al arroyo se presenta la mayor densidad de estructuras agrícolas, que incluyen cuadros de cultivo de grandes dimensiones asociados a muros de contención, despedres y recintos simples de planta circular. Las parcelas de cultivo en este asentamiento se constituyen de dos maneras: por una parte, un diseño incluye la combinación de montículos de despedre asociados a muros de contención del suelo que forman estructuras cuadrangulares $y$, por otra, se observan 


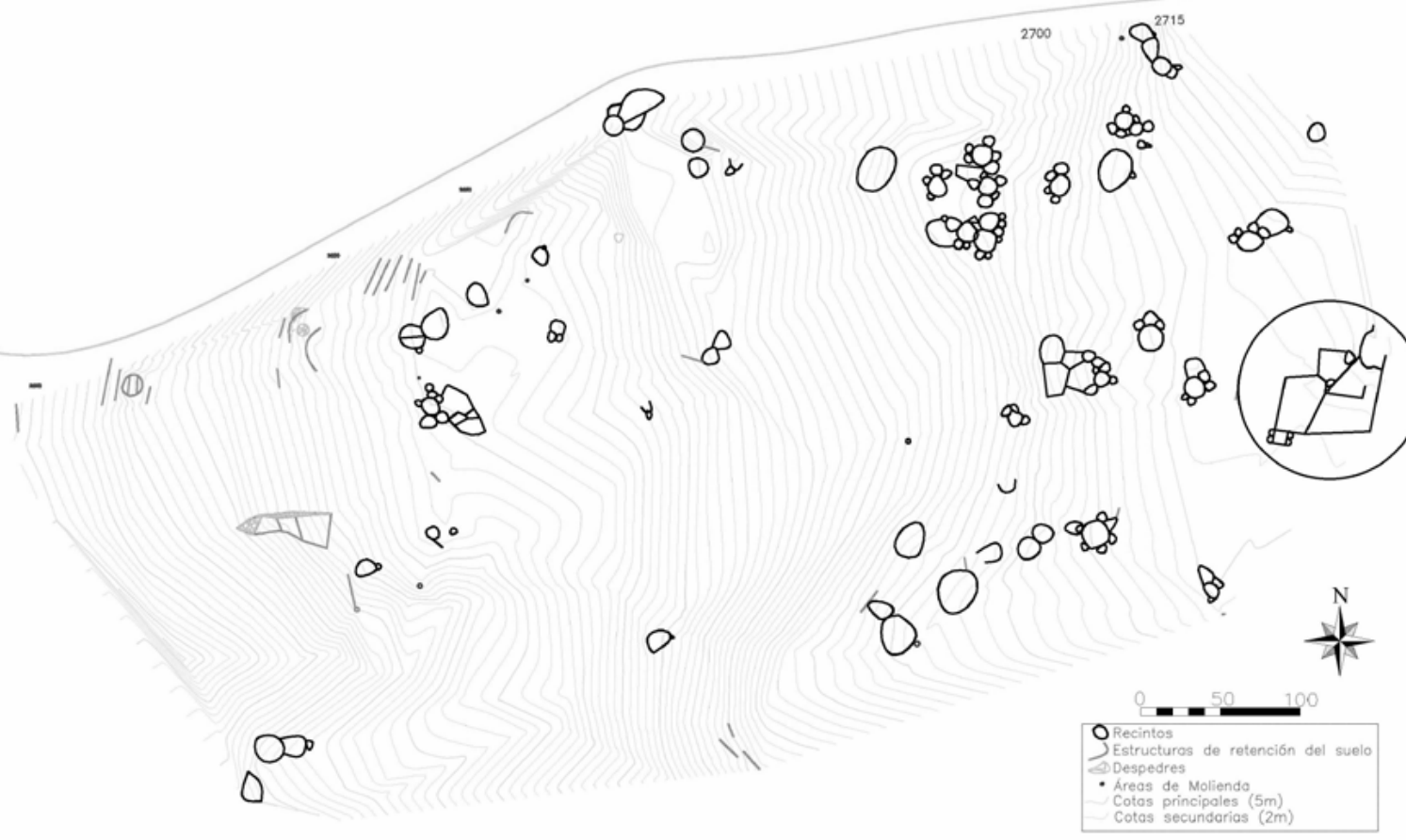

Figura 8. Sitio arqueológico La Bolsa 3 (2700 msnm). La estructura excepcional está señalizada con un círculo.

conjuntos de paramentos de retención dispuestos de forma paralela, distanciados por 2 o $3 \mathrm{~m}$. En asociación a estos campos se han registrado espacios de molienda extramuros (bloques metamórficos con concavidades).

En las transectas trazadas para recolección superficial en LB3 se recuperaron 808 fragmentos de cerámica. Las proporciones de grupos tecnotipológicos en la totalidad de las mismas son bastante homogéneas, presentándose un alto porcentaje de fragmentos correspondientes a ordinario rojo sin baño y, en menor proporción, rojo fino sin baño.

\section{Ocupaciones del segundo milenio}

En la porción este de LB3, se destaca por sus características extraordinarias, una estructura de forma angular de nueve recintos agrupados: tres recintos cuadrangulares grandes con subdivisiones internas que incluyen algunos de formas semicirculares (Figura 8). Sus características se asemejan a las de la estructura "excepcional" de LB2, diferenciándose ambas notablemente del resto por su forma, tamaño y concentración.

La materia prima utilizada para su construcción es similar a las demás del sitio, esto es, esquistos micáceos y graníticos locales que abundan en el sector y en los arroyos adyacentes. Las características de los muros se asemejan a los registrados para el primer milenio aunque la forma de planta es semejante a las correspondientes para el período Tardío. El material arqueológico recolectado en esta área se diferencia de los demás sectores por detectarse la presencia exclusiva de tipos santa maría bicolor (SB), blanco sobre rojo pulido (BsRP) y belén negro sobre rojo (BNsR). 


\section{Agricultura en el PDR: discutiendo las primeras evidencias en el sector norte del valle de Tafí}

Resulta importante diferenciar dos puntos en nuestra interpretación, que se expresan en una escala micro, relacionada al uso que tuvieron estas estructuras excepcionales, y otro más general de escala macro que se refiere al contexto de estas ocupaciones, esto es, ¿son producto de procesos locales o extralocales (satélites de Yocavil, p.e.)? Respecto a esta última pregunta, se destacan dos planteos principales. Uno que señala que estas estructuras excepcionales formaron parte de un plan de complementariedad económica para extraer recursos y proveer a las zonas centrales (p.e. valle de Yocavil), en un contexto de escasez de recursos, jerarquías sociales florecientes y conflictos sociales entre poblaciones vecinas ( $\mathrm{Ta}$ rragó, 2000). Y otro que sostiene que las evidencias arqueológicas presentes en el valle indicarían continuidades en la ocupación desde el primer milenio, pero con transformaciones sustanciales en cuanto a la densidad poblacional, características de la materialidad y maneras de establecerse en el paisaje (Manasse, 2002).

Las estructura excepcional registrada en La Bolsa 2 presenta un registro arqueológico que se corresponde a un uso esporádico, de tipo logístico producto de la secuencia que implica un tipo de gestión agrícola que se diferencia de la recurrente casa-campo asociada al primer milenio de la Era. En el caso de la detectada en La Bolsa 3 restan trabajos sistemáticos a futuro, aunque los primeros estudios realizados (prospección y recolección superficial) acompañan esta idea.

El alero-refugio es un tipo de estructura similar a la denominada "Jant'a", esto es, un refugio de vivienda en el marco de la realización de actividades de producción durante períodos cortos, es decir, un espacio de uso logístico por parte de un grupo reducido de personas. Se encuentran en toda el área andina tanto en la actualidad como en el pasado, y han sido mencionadas por diversos investigadores del NOA, aunque las publicaciones específicas son escasas (Nielsen, 2001). La necesidad de permanecer por períodos de varios días para atender los cul- tivos cobra expresión arqueológica en la existencia de puestos de ocupación temporaria en el NOA y se registra principalmente durante el período de Desarrollos Regionales o Tardío (p.e. Alfarcito, Quebrada de Calete, Sud Lípez, Pozuelos, etc.).

Para poder definir la trayectoria histórica de este tipo de asentamiento resulta fundamental entender en qué contexto tuvo lugar su uso. La datación radiocarbónica constata una ocupación durante el siglo XIII en LB2; y la evidencia arqueológica podría acompañar el planteo de un uso estratégico para la extracción de recursos agrarios en tiempos coyunturales por parte de poblaciones del valle de Yocavil que pasaban por un proceso de violencia y escasez de recursos (Tarragó, 2000). Sin embargo, nuevas versiones relativizan algún estado de guerra y de poder jerárquico (Acuto, 2008; Nielsen, 2003) que buscara absorber recursos extralocales en los valles vecinos, lo que complicaría la definición del rol del refugio agrícola en el valle. En este sentido, cobraría mayor validez el planteo de Manasse sobre la existencia de trayectorias locales sin registrarse evidencia de espacios satélites o enclaves como resultado de procesos no locales (Tartusi y Núñez Regueiro, 1993; Tarragó, 2000). De esta forma, podría tratarse de grupos de familias que residirían al sur del valle y que usaban este sector septentrional durante períodos estivales para la producción agraria, instalándose allí solo los días de mayor demanda de trabajo (Manasse, 2011).

Resulta válido señalar que el uso de estos "refugios" durante períodos vinculados a las actividades agrícolas ya se registra en el primer milenio al sur del valle de Tafí (Berberián, 1994). En proximidad a un montículo de uso ritual (González, 1960; González y Núñez Regueiro 1960), se excavó un despedre de cultivo que contenía un pequeño recinto asociado $\mathrm{y}$ un deflector de aire dispuesto de forma oblicua junto al acceso. Allí, Berberián y su equipo registraron restos de lo que habría sido un puesto de uso temporal durante los períodos especiales de producción. La evidencia era escasa pero clara en lo referente a las actividades allí realizadas: un tubo de cerámica (i.e. fumar), un tortero de cerámica y agujas de hueso (i.e. tejer), un puco de pequeńas dimensiones y una olla del grupo rojo grueso de paredes muy finas y cubiertas por una gruesa capa de hollín 


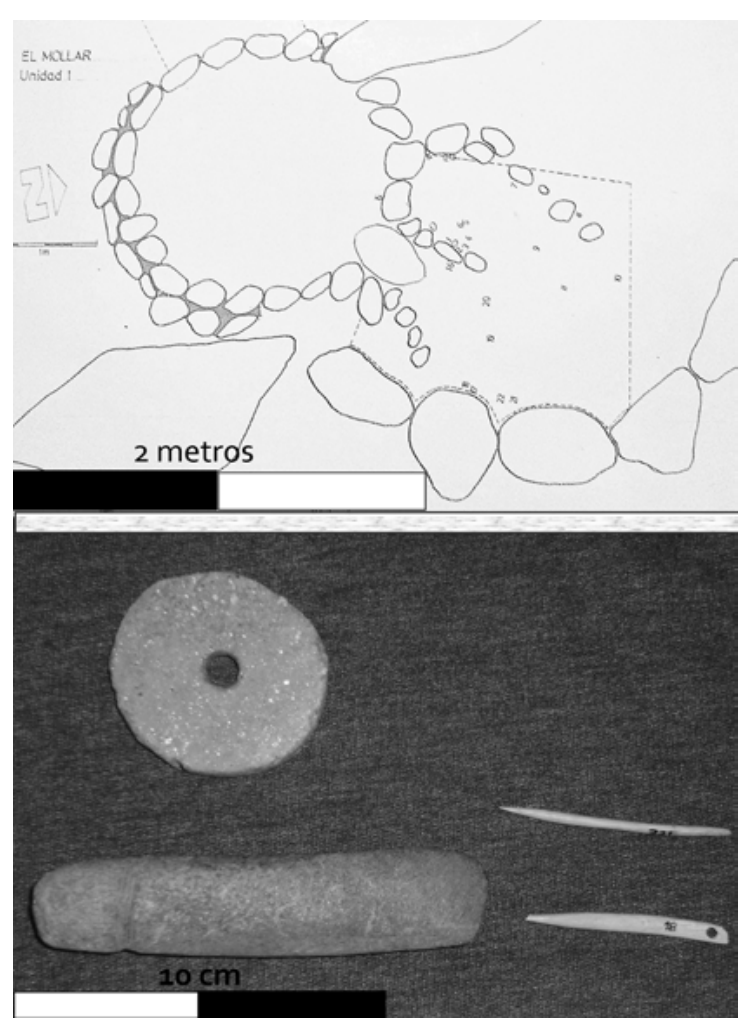

Figura 9. Planta del recinto excavado por Berberián y los restos arqueológicos hallados en la excavación (Plano e imágenes, gentileza E. Berberián).

(i.e. alimentación) y algunas lascas de cuarzo (i.e. corte, preparación de alimentos) (Figura 9) (Berberián, 1994). Los registros etnográficos sobre jant’as y puestos agrícolas se condicen con la materialidad hallada; actividades como tejer y fumar son practicadas durante los momentos de descanso y ocio en el marco de la secuencia de trabajo agrario.

Por otro lado, respondiendo a un encargo de la Comunidad Indígena del Pueblo Diaguita del Valle de Tafí, recientemente hemos realizado prospecciones en el sector noreste del cerro Ampuqcatao o Pelao (Tafí del Valle) (Salazar et al., 2014), que constatan su ocupación durante un largo período que incluye el primer milenio de la era y primera mitad del segundo. A lo largo de las distintas transectas realizadas se identificaron unidades residenciales circulares (características del primer milenio en esta región), áreas de molienda adyacentes a cursos de agua, estructuras productivas circulares y rectangulares y rocas grabadas. En uno de los sectores prospectados se localizó un pequeño alero rocoso en cercanía a un sector de múltiples terrazas paralelas, formadas por muros de entre 5 y $20 \mathrm{~m}$ de largo, que tenían como fin mejorar la productividad de los suelos mediante la generación de espacios horizontales a partir de espacios inclinados (Figura 10). En su interior se detectó un afloramiento rocoso grabado con más de 25 cavidades circulares pequeñas (de no más de 2 $\mathrm{cm}$ de diámetro). Las dimensiones del alero permiten el acceso de pocas personas, y por su asociación directa al espacio de cultivo podríamos pensar en un "refugio" de similares características a los ya mencionados. En referencia a los grabados, sostenemos en este caso que, al encontrarse el grabado en un espacio de escasa visibilidad, su significado puede estar más relacionado con algún tipo de actividad ritual, con la necesidad de marcar un rasgo natural importante o con su utilización como medio para transmitir información (Williams et al., 2005; Martel, 2006).

La presencia de dos refugios en otras áreas del valle aporta un puntapié inicial para indagar en nuevas interpretaciones acerca de la historia del paisaje agrario. Estos espacios de uso corto han sido parte de un circuito de prácticas de cultivo que se remontan desde mediados del primer milenio y que se continuaron por lo menos hasta el siglo XIII. La agricultura se concibe como un fenómeno que participa activamente de las coyunturas diversas de un mundo social, lo que la hace un indicador relevante al momento de entender los procesos históricos prehispánicos (Korstanje et al., 2015).

En el presente caso de estudio, se reconocen diferencias entre los campos de cultivo correspondientes al primer y segundo milenio de la era. Por un lado, tenemos una agricultura de manejo doméstico basada en una manifestación espacial recurrente que podríamos denominar casa-campo, con una mayor dispersión en el paisaje y variabilidad en sus construcciones (i.e. muros de contención, andenes, terrazas, canales, puestos de ocupación temporaria para la producción, etc.), y por otro, una serie de complejos de recintos agrupados, posicionados sin asociación a viviendas particulares (i.e. aislados) y de formas angulares. Este contraste no se materializa de manera abrupta en el paisaje, aunque es posible observar que hay formas espaciales y laborales que tienen continuidad, como el uso de técnicas similares de construcción de muros, las plantas cultivadas, 

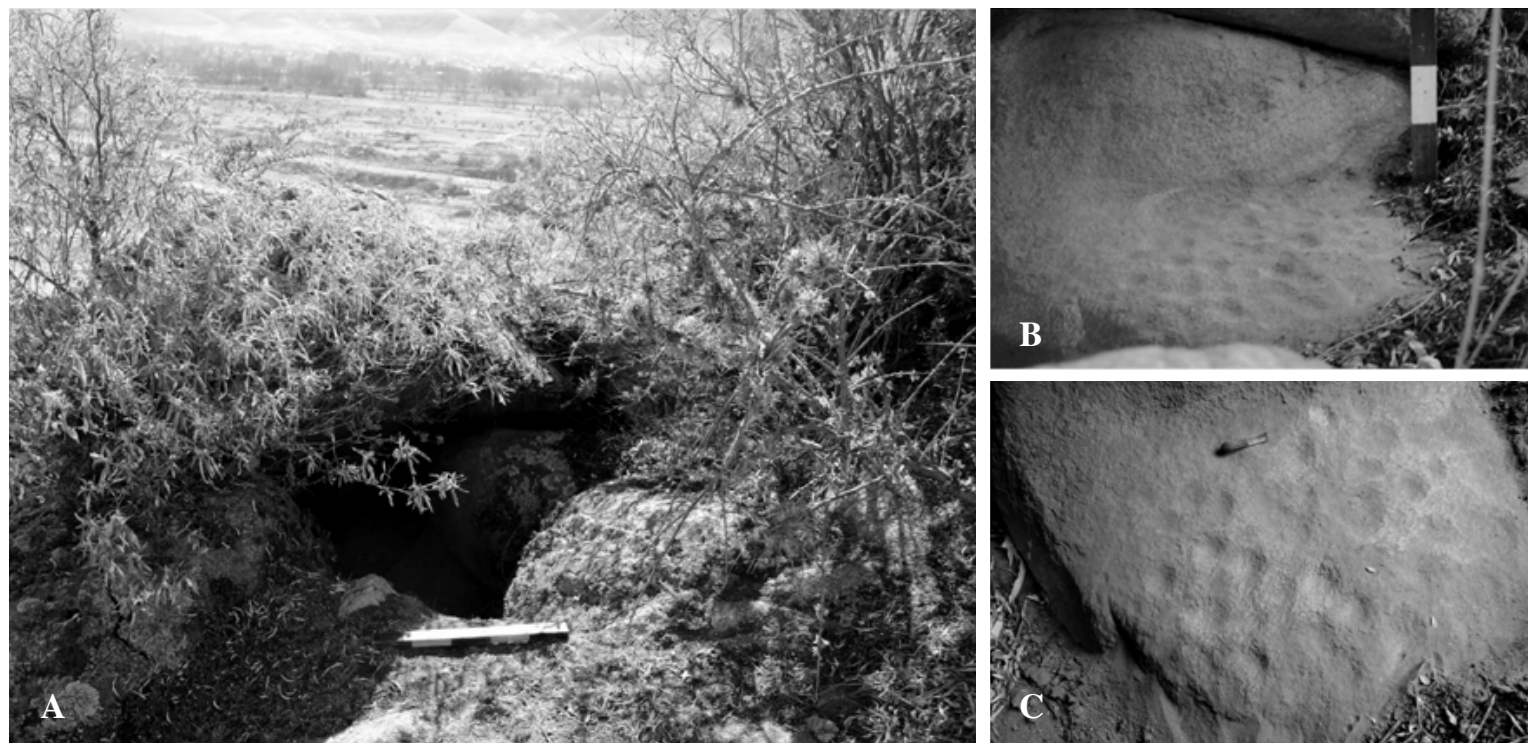

Figura 10. A. Vista frontal del Alero. B y C. Vista detallada de las cavidades registradas en el interior.

los espacios seleccionados para la producción, el uso de recintos para el cultivo y de puestos de ocupación temporaria, etcétera. En este sentido, se observan continuidades en algunas lógicas de la organización del trabajo agrícola, aunque también hay diferencias notables que serían parte de nuevas manifestaciones económico-políticas del valle.

Nuestro pensamiento acerca del contexto económico-político de estas estructuras excepcionales fue virando a medida que las investigaciones arqueológicas en el área se hicieron más sistemáticas. En las primeras etapas, que incluyeron prospección y relevamiento arqueológico del sitio, nuestras hipótesis se acercaban al planteo de Tarragó (2000) sobre el rol del valle en el período de Desarrollos Regionales, porque observábamos estructuras que en morfología distaban mucho de las encontradas comúnmente en el área, asemejándose a las de los valles vecinos, lo que resultaba lógico cuando sumábamos la presencia de cerámica del tipo "santamariana" en la superficie de estos lugares excepcionales. No obstante, nuestra idea acerca del "contexto" fue cambiando a medida que se fueron incrementando evidencias en el valle, generadas por otros investigadores sobre procesos locales (Manasse, 2002; Patané Aráoz, 2008; Páez y Plá, 2015), pero también cuando a través de las excavaciones reconocimos que la cerámica habría sido manufacturada en la localidad, que las técnicas constructivas de los muros eran similares a las del primer milenio y que las estrategias de cultivo no distaban mucho de las preexistentes (i.e. agricultura a secano, mismos cultígenos, escasa presencia de técnicas de fertilización y similares manejos en las técnicas de nivelación del terreno).

Encontramos entonces dos lógicas diferentes para la selección de los lugares para habitar y cultivar: vivienda y campo en el primer milenio (Tarragó, 1999) y otra, con un patrón que se repite en el NOA "campo agrícola segregado de la vivienda". Esta segregación, en general, se interpreta como una expresión espacial de aumento demográfico, intensificación agrícola y procesos de jerarquización social (Laguens, 2004; Figueroa, 2008). No obstante, en este caso particular, la densidad poblacional ha disminuido notablemente, la agricultura no ha innovado en técnicas y estrategias para aumentar la producción y hasta el momento no se registran evidencias de centralización de poder o jerarquización social. De esta forma, nos encontramos con una lógica espacial propia del segundo milenio en el NOA, pero que no habría sido impulsada por los "motores" que la literatura arqueológica neoevolucionista suele atribuirle, esto es, el modelo teórico que sostiene la existencia de una lógica de enclaves que consisten en asentamientos gestionados desde áreas centrales que extraen de los marginales -valle de Tafí, en este caso- los recursos para la obtención de excedentes. 


\section{Agradecimientos}

El presente trabajo no habría sido posible sin la colaboración de los integrantes del equipo "Arqueología del extremo Sur de Cumbres Calchaquíes", especialmente a Julián Salazar, Stefanía Chiavassa Arias y Juan Montegú. Otro aporte importante y que agradecemos es el efectuado por la Universidad Nacional de Córdoba, el CONICET y el de Cristina Fernández de Kirchner por su apoyo incondicional a la ciencia. Un especial agradecimiento para el Dr. Berberián que nos permitió acceder al registro fotográfico de sus informes de investigación. Las excavaciones y prospecciones han sido realizadas con el correspondiente permiso del Ente Cultural de la Provincia de Tucumán y con el acuerdo de la Comunidad Indígena del Pueblo Diaguita del valle de Tafí. Estamos agradecidas de los comuneros del valle, especialmente de la familia Cruz que nos permitió acceder a los terrenos y de Benito Cruz por su ayuda constante.

\section{Referencias citadas}

Acuto, F. (2008). Materialidad, espacialidad y vida social. Reinterpretando el Período Prehispánico Tardío de los Andes del Sur. En Sed non satiata II. Acercamientos sociales en la arqueología latinoamericana (pp. 159-193). Córdoba: Brujas.

Berberián, E. (1994 Ms.). Sistemas de asentamiento en el Valle de Tafí. Informe elevado al CONICET. Manuscrito.

Berberián, E. y Giani. L. (1999). Consideraciones acerca de la variabilidad formal en el diseño de las plantas de arquitectura en el NOA durante las etapas Formativas y de Desarrollos Regionales. En Actas del XII Congreso Nacional de Arqueología Argentina, Tomo 1 (pp. 83-88). La Plata.

Berberián, E. y Nielsen, A. (1988). Cap 2: Sistemas de Asentamiento Prehispánicos en el Valle de Tafí. En Sistemas de Asentamiento Prehispánicos en el Valle de Tafi (pp. 21-51). Córdoba: Editorial Comechingonia.

Carandini, A. (1997). Historias en la tierra. Manual de excavación arqueologica. Barcelona: Crítica.
Caria, M. A. y Garralla, S. (2003). Caracterización arqueopalinológica del sitio Ticucho 1 (Cuenca Tapia-Trancas) Tucumán, Argentina. En Actas Cuaternario y Geomorfología, Segundo Congreso Argentino de Cuaternario y Geomorfologia (pp. 421-428), San Miguel de Tucumán.

Caria, M., Oliszewski, N., Gómez Augier, J., Pantorrila, M. y Gramajo Bühler, M. (2010). Formas y espacios de las estructuras agrícolas prehispánicas en la Quebrada del río de Los Corrales (El Infiernillo-Tucuman). En $\mathrm{Ar}$ queología de la agricultura: casos de estudio en la región andina argentina (pp. 144-165), Universidad Nacional de Tucumán.

Chiavassa Arias, S. (2015). Reinterpretando la marginalidad: el rol de las prácticas pastoriles en la configuración del paisaje aldeano en una comunidad del Valle de Tafí (1-1000 AD). En Arqueogasta III- XIV Congreso Nacional de Estudiantes de Arqueología (pp. 39-42). Córdoba, Argentina.

Di Lullo, E. (2012). La casa y el campo en la Quebrada de Los Corrales (El Infiernillo, Tucumán): reflexiones sobre la espacialidad en el $1^{\circ}$ milenio d.C. Comechingonia, 16, 85-104

Figueroa, G. (2008). Los sistemas agrícolas del valle de Ambato, Catamarca, siglos VI a XI d.C. Intersecciones en Antropología, 9, 313-317.

Franco Salvi, V. (2012). Estructuración social y producción agricola prehispánica durante el primer milenio d.C. en el Valle de Tafi (Tucumán, Argentina). Tesis Doctoral, Universidad Nacional de Córdoba.

Franco Salvi, V. y Berberián, E. (2011). Prácticas agrícolas de sociedades campesinas en el Valle de Tafí (100 a.C.900 d.C.). Revista de Antropología, 24, 119-145.

Franco Salvi, V., Salazar, J. y Berberián, E. (2014). Paisajes persistentes, temporalidades múltiples y dispersión aldeana en el valle de Tafí (provincia de Tucumán, Argentina). Intersecciones en Antropología, 15, 307-322.

Giovanetti, M., Spina, J., Páez, M. C., Cochero, G., Rossi A. y Espósito, P. (2013). En busca de las festividades del Tawantinsuyu. Análisis de los tiestos de un sector de descarte de El Shincal de Quimivil. Intersecciones en Antropología, 14, 67-82. 
Glascock, M. (2016). Analysis of Obsidian Artifacts from Northwestern Argentina by Energy Dispersive X-Ray Fluorescence. Report of Archaeometry Laboratory. Research Reactor Center. University of Missouri. Columbia.

González, A. R. (1955). Contextos culturales y cronología en el área central del Noroeste Argentino. Anales de arqueología y etnología, 11, 7-32.

Gónzalez, A. R. (1960). Nuevas fechas de la cronología arqueológica argentina obtenidas por el método de radiocarbón (IV). Resumen y perspectivas. Revista del Instituto de antropología, 1, 303-331.

González, A. y Núñez Regueiro, V. (1960). Preliminary Report on Archaeological Research in Tafí del Valle, NW Argentina. In Akten del 34 amerikanisten Kongress, 18-25. Viena.

González, L. R. y Tarragó, M. N. (2005). Vientos del Sur. El valle de Yocavil (Noroeste argentino) bajo la dominación incaica. Estudios Atacameños, 29, 67- 95.

Harris, E. (1991). Principios de estratigrafía arqueológica. Barcelona: Crítica.

Korstanje, M. A. (2005). La organización del trabajo en torno a la producción de alimentos en sociedades agropastoriles formativas (Provincia de Catamarca, República Argentina). Tesis Doctoral en Arqueología. Facultad de Ciencias Naturales e IML, Universidad Nacional de Tucumán.

Korstanje, M. A. (2009). Microfósiles y Agricultura Prehispánica: Primeros Resultados de un Análisis Múltiple en el N.O.A. En Zucol, A. F.; Osterrieth, M.; Brea, M. y Borrelli, N. (Eds.). Análisis fitoliticos de vegetación, suelos, sedimentos y sitios arqueológicos: estado actual de su conocimiento en América del Sur (pp. 249- 263). Mar del Plata.

Korstanje, M. A. y Babot, M. del P. (2007). Microfossils characterization from south Andean economic plants. En Madella, M. y Zurro, D. (Eds.), Plants, people and places. Recents studies in phytolith analysis (pp. 41-72). Oxford: Oxbow books.

Korstanje, M. A. y Cuenya, P. (2010). Ancient agriculture and domestic activities in north western Argentina: a contextual approach studying silica phytoliths and other microfossils in soils. Environmental Archaeology, 15, 43-63.
Korstanje, M. A, Quesada, M., Franco Salvi, V., Lema, V. y Maloberti, M. (2015). ¿Cómo son los paisajes agrarios del formativo? En Korstanje, M. A., Lazzari, M., Basile, M., Bugliani, F., Lema, V., Pereyra Domingorena, L. y Quesada, M. (Eds.). Crónicas materiales precolombinas. Arqueología de los primeros poblados del Noroeste Argentino (pp. 721-749), Buenos Aires.

Laguens, A. (2004). Arqueología de la diferenciación social en el valle de Ambato, Catamarca, Argentina (s. II-VI d.C.): El actualismo como metodología de análisis. Relaciones de la Sociedad Argentina de Antropología, XXIX, 137-161.

Latour, B. (1999). Pandora's Hope. Essays on the reality of science studies. England: Harvard University Press.

Latour, B. (2000). The Berlin key or how to do words with things. En Matter, Materiality and Modern Culture (pp. 10-21), New York: Routledge.

Latour, B. (2005). Reassembling the Social: An Introduction to Actor-Network-Theory. Oxford: Oxford University Press.

Manasse, B. (1997). Consideraciones preliminares para un rescate arqueológico en el este de Tafí del Valle, provincia de Tucumán, República Argentina. Cuadernos, 9 Facultad de Humanidades y Ciencias Sociales, Universidad Nacional de Jujuy.

Manasse, B. (2002). Caracterización arqueológica del norte de la estancia de Los Cuartos, Tafí del Valle, provincia de Tucumán. En Actas XIII Congreso Nacional de Arqueologia Argentina 1999. Tomo 2. Córdoba: Brujas.

Manasse, B. (2007). Tiempo antes de la conquista española en el Valle de Tafí. En Arenas, P., Manasse, B. y Noli, E. (Comps.). Paisajes y procesos sociales en Tafí del Valle (pp. 135-164). Tucumán, Argentina. Imprenta de la Universidad Nacional de Tucumán.

Manasse, B. (2011) Ms. Arqueología en el borde andino del Noroeste Argentino: sociedades del último milenio en el valle de Tafí, Prov. de Tucumán-República Argentina (Tesis Doctoral inédita). Universidad Nacional de la Plata, Argentina. 
Marchegiani, M., Palamarczuk, V., Reynoso, A. (2009). Las urnas Negro sobre Rojo tardías de Yocavil (Noroeste Argentino). Reflexiones en torno al estilo. Boletín del Museo Chileno de Arte Precolombino, 14, 69-98.

Martel, A. R. (2006). Arte rupestre y espacios productivos en el Formativo: Antofagasta de la Sierra (Puna meridional argentina). En Tramas en la piedra. Producción y usos del arte rupestre (pp. 157-167). Buenos Aires: Sociedad Argentina de Antropología, AINA, WAC.

Martínez, J. G., Mauri, E. P., Mercuri, C., Caria, M. y Oliszewski, N. (2013). Mid-Holocene human occupations in Tucumán (northwest Argentina). Quaternary International, 307, 86-95.

McLaughlin, R.B. (2012). An introduction to the microscopical study of diatoms. Delly, J. G. \& Gill, S. In http:/ / www.microscopy-uk.eu/ diatomist/rbm_US_Royal .pdf

Nastri, J. (2005). Arqueología en Catamarca. El valle de Santa María de Yocavil: Cerámica Santamariana: Iconografía calchaquí. Encrucijadas, 31, 66-70.

Nielsen, A. (2001). Ocupaciones Formativas en el Altiplano de Lípez - Potosí, Bolivia. Textos antropológicos, 13, 265-285.

Nielsen, A. (2003). La Edad de los Auca Runa en la Quebrada de Humahuaca (Jujuy, Argentina). Memoria Americana, 11, 73-107.

Nielsen, A. (2007). Celebrando con los Antepasados. Arqueología del Espacio Público en Los Amarillos (Quebrada de Humahuaca, Jujuy, Argentina). Buenos Aires: Mallku.

Nielsen, A. (2009-2011). Hacia una arqueología de la guerra como si la práctica importara. Mundo de antes, 6-7, 11-25.

Oliszewski, N. (2011). Ocupaciones prehispánicas en la Quebrada de Los Corrales, El Infiernillo, Tucumán (ca. 2500-600 años AP). Comechingonia, 14, 127-144.

Orgaz, M. (2012). Chicha y aloja. Inkas y autoridades locales en el sector meridional del valle de Yocavil - Catamarca - Argentina. Surandino Monográfico, 2, 1-38.

Páez, M. C. (2014). Tafy Valley (Argentine Northwest). Rethinking the local positions in the global context of SXV. The International Journal of Humanities \& Social Studies, 2, 99-106.
Páez, M. C. y R. Plá (2015). Producción local de objetos cerámicos durante los períodos Tardío e Inca en el valle de Tafí (Tucumán, Argentina). Chungara. Revista de Antropología Chilena, 47, 429-440.

Patané Aráoz, C. J. (2008-2010). El Pukará de las Lomas Verdes (Tafí del Valle, Tucumán). Medio siglo después. Cuadernos del Instituto Nacional de Antropología y Pensamiento Latinoamericano, 22, 165-178.

Pearsall, D., Chandler-Ezell, K. y Chandler-Ezell, A. (2003). Identifying maize in neotropical sediments and soil using cob phytoliths. Journal of Archaeological Science, 30, 611-627.

Quesada, M. (2005). Prácticas cotidianas y estructuras de larga duración. La reproducción del oasis de Tebenquiche Chico. Trabajo presentado al Taller Procesos Sociales Prehispánicos en los Andes Meridionales. Instituto Interdisciplinario Tilcara. Universidad de Buenos Aires.

Quesada, M. y Korstanje, M. A. (2010). Cruzando estructuras: el espacio productivo y su entorno percibido desde las prácticas cotidianas. El hábitat prehispánico. Arqueología de la arquitectura y de la construcción del espacio organizado (pp.123-153) Editorial UNJu.

Salazar, J. (2010). Reproducción social doméstica y asentamientos residenciales entre el 200 y el 800 d.C. en el Valle de Tafi, Provincia de Tucumán. Tesis Doctoral. Universidad Nacional de Córdoba.

Salazar, J., Franco Salvi, V. L., Berberián, E. E. y Clavero, S. (2007). Contextos domésticos del valle de Tafí, Tucumán, Argentina (200-1000 AD.). Werken, 10, 25-48.

Sampietro Vattuone, M. M. (2002). Contribución al conocimiento geoarqueológico del valle de Tafi, Tucumán (Argentina). Tesis Doctoral. Universidad Nacional de Tucumán.

Sayago, J. M., Sampietro, M. M., Caria, M. y Collantes, M. M. (2003). Paleoclimatic changes and human crisis in Northwest Argentina during the European medieval warm period. En Quaternary Climatic Changes and Environmental Crisis in the Mediterranean Region (pp. 8188). Madrid: Imprenta Universidad de Alcalá. Alcalá de Henares. 
Scattolin, M. C. (2001). Organización residencial y arquitectura en el Aconquija durante el primer milenio d.C. En Actas del XIII Congreso Nacional de Arqueología (pp. 439-449) Tomo I. Córdoba.

Scattolin, M. C. (2010). La organización del hábitat precalchaquí (500 A.C. - 1000 D.C.). En El hábitat prehispánico. Arqueología de la arquitectura y de la construcción del espacio organizado (pp. 13-52). Jujuy: Editorial UNJu.

Tarragó, M. N. (1999). El Formativo y el surgimiento de la complejidad social en el Noroeste argentino. En Formativo Sudamericano: una reevaluación (pp. 302-307). Quito: Abya-Yala.
Tarragó, M. N. (2000). Chacras y pukaras: Desarrollos Sociales Tardíos. En Nueva Historia Argentina. Tomo I (pp. 257-300) Buenos Aires: Editorial Sudamericana.

Tartusi, M. y Núńez Regueiro, V. (1993). Los centros ceremoniales del NOA. Publicaciones No 5 Serie: Ensayos y Crítica $N^{o}$ 1. Instituto de Arqueología- Universidad Nacional de Tucumán.

Williams, V., Villegas, M. P., Gheggi, M. S. y Chaparri, M. G. (2005). Hospitalidad e intercambio en los valles Mesotermales del Noroeste Argentino. Boletín de Arqueología PUCP, 9, 335-372. 
